\title{
A Quasi-Experimental Study of After-Event Reviews and Leadership Development
}

\author{
D. Scott DeRue \\ University of Michigan \\ Jennifer D. Nahrgang \\ Arizona State University \\ John R. Hollenbeck \\ Michigan State University \\ Kristina Workman \\ University of Michigan
}

\begin{abstract}
We examine how structured reflection through after-event reviews (AERs) promotes experience-based leadership development and how people's prior experiences and personality attributes influence the impact of AERs on leadership development. We test our hypotheses in a time-lagged, quasi-experimental study that followed 173 research participants for 9 months and across 4 distinct developmental experiences. Findings indicate that AERs have a positive effect on leadership development, and this effect is accentuated when people are conscientious, open to experience, and emotionally stable and have a rich base of prior developmental experiences.
\end{abstract}

Keywords: leadership, leadership development, reflection, after-event review, personality

Early approaches to leadership emphasized that leaders are born and not made, but this view has given way to a focus on developing individuals' capacity to engage effectively in leadership roles, behaviors, and processes (Day, 2000; Day \& Zaccaro, 2004; McCall, 2004). Indeed, many organizations view leadership development as a source of sustainable competitive advantage and are investing in its development accordingly (McCall \& Hollenbeck, 2002). For example, U.S.based organizations in 2009 invested \$12 billion, or 24\% of their training budgets, in leadership development (O'Leonard, 2010).

Although organizations routinely invest in formal leadership training, there is growing recognition that most leadership development occurs via experiences occurring outside of formal training (McCall, Lombardo, \& Morrison, 1988; McCauley, Ruderman, Ohlott, \& Morrow, 1994; Ohlott, 2004). Supporting this premise, prior research has established that experiences requiring individuals to perform novel and challenging jobs promote leadership development and that

D. Scott DeRue, Management and Organizations, University of Michigan; Jennifer D. Nahrgang, Department of Management, Arizona State University; John R. Hollenbeck, Department of Management, Michigan State University; Kristina Workman, Management and Organizations, University of Michigan.

We thank the Society for Human Resource Management Foundation for its financial support of this project. We thank Karyll Shaw, associate dean for MBA and professional master's programs at the Broad College of Business (Michigan State University), for her guidance and support during this project. We also thank Susan J. Ashford for her helpful comments on an earlier version of this paper.

Correspondence concerning this article should be addressed to D. Scott DeRue, Management and Organizations, Stephen M. Ross School of Business, University of Michigan, 701 Tappan Street, Ann Arbor, MI 48109. E-mail: dsderue@umich.edu 
individuals who are learning oriented, open to criticism, and who have access to support and feedback are particularly proficient at learning leadership via experience (DeRue \& Wellman, 2009; Dragoni, Tesluk, Russell, \& Oh, 2009; McCauley et al., 1994; Spreitzer, McCall, \& Mahoney, 1997). As McCall (2004) stated, "The primary source of learning to lead, to the extent that leadership can be learned, is experience" (p. 127).

However, there are also unique aspects of leadership that draw into question the core assumptions of experiential learning theory and make experience-based leadership development especially challenging relative to experiential learning in other domains. In particular, leadership experiences are ambiguous, involve multiple stakeholders, entail a multitude of inputs, and often require individuals to take on highly visible and personally risky roles (Heifetz \& Linsky, 2002; McCall \& Hollenbeck, 2002; Pfeffer, 1977)-all of which can interfere with experiential learning. In this article, we foreground the importance of structured reflection in overcoming these challenges and develop and test a set of hypotheses about how after-event reviews (AERs) enable people, especially those with certain career experience and personality profiles, to get the most out of their developmental experiences. Consistent with Ellis and Davidi (2005, p. 857), we define an AER as a "learning procedure that gives learners an opportunity to systematically analyze their behavior and to be able to evaluate the contribution of its components to performance outcomes."

In foregrounding the value of AERs in leadership development and specifying the types of people who benefit most from AERs, we make three contributions to the literature. First, most research on leadership development is grounded in experiential learning theories that assume individuals can construct a rich understanding of their own experiences and then generalize the lessons of those experiences to improve their performance (Boud \& Walker, 1991; Kolb, 1984; Mezirow, 1991). Yet, leadership development research is replete with examples where individuals struggle to learn from experience or even learn the wrong lessons (DeRue \& Wellman, 2009; McCall et al., 1988). Drawing from research on the ambiguities and complexities of leadership (Pfeffer, 1977; Roese, 1997; Yammarino \& Bass, 1991), we challenge the assumption that individuals are able to systematically process and learn from their own leadership development experiences. We then propose that AERs provide a structured analysis and elaboration of experiential data that enables individuals to learn from experience and enhance their performance of leadership behaviors.

Our second contribution is that we address the following puzzle observed in prior research (DeRue \& Wellman, 2009; Ellis, Gan- zach, Castle, \& Sekely, 2010; McCall \& Hollenbeck, 2002; McCall et al., 1988): Why can two people go through similar developmental experiences, or the same AER process, and come out of those experiences or AERs with different learning and development outcomes? Existing theory and research favor the type of developmental experience (McCauley et al., 1994; Ohlott, 2004) or the type of AER (Ellis et al., 2010; Ellis, Mendel, \& Nir, 2006) as the primary explanation for learning and development, but these studies do not explain why two people who go through the same experience and AER process can achieve different outcomes. We posit that the missing element is an understanding of how attributes of the focal actor determine the extent to which AERs enable individual development. In this article, we focus on a set of personal attributes that theoretically should enhance the extent to which AERs can promote experience-based leadership development. This focus on personal attributes is particularly important because it shifts the emphasis beyond what type of AER (e.g., filmed vs. personal; success vs. failure-focused; Ellis et al., 2010) or what type of experience (e.g., successes 
or failures; Ellis \& Davidi, 2005) is most developmental and instead foregrounds how the focal actor's attributes can shape the validity of AERs.

A third contribution of the present study is related to the gen- eralizability of prior research on AERs and its application to leadership development in organizations. To date, AERs have been studied in a controlled military setting with males who were engaged in individual-based, navigation exercises (Ellis \& Davidi, 2005), in laboratory settings with undergraduate students engaged in individual-based tasks (Ellis et al., 2006, 2010), and in controlled, individual-based work simulations (Anseel, Lievens, \& Schollaert, 2009). In addition, these tasks were performed over relatively short periods of time, in some cases less than 1 hour and at most up to 3 weeks. These learning tasks and contexts are potentially quite different than leadership in organizations, where the development process is more ambiguous and ill-defined and requires that people learn and exhibit improvement over longer periods of time while working on complex and interdependent tasks (McCauley \& Van Velsor, 2004). Thus, it is not clear that the findings from prior AER research will generalize to leadership development. Our study extends prior research by demonstrating the positive impact of AERs on experience-based leadership development and specifies for which types of people AERs will be most beneficial.

\section{Hypothesis Development}

Consistent with prior research (Day \& Zaccaro, 2004; Klein \& Ziegert, 2004), we define leadership development as a positive change in the effective use of leadership behaviors. In developing our hypotheses, we first identify some of the unique challenges associated with experience-based leadership development. We then explain how AERs enhance leadership development by addressing these challenges. We conclude by developing hypotheses about how individuals' prior experience and personality determine the value of AERs in leadership development.

\section{Challenges to Experience-Based Leadership Development}

Experiential learning theories generally adopt a constructivist perspective on learning, which proposes that individual development occurs as people reflect on their lived experiences and then generalize from those experiences to develop new mental models, skills, and knowledge that will improve performance in future experiences (Boud \& Walker, 1991; Dewey, 1938; Fenwick, 2003; Knowles, 1970; Kolb, 1984; Mezirow, 1991). In this sense, constructivism recognizes that most workplace learning, including leadership development, occurs as people actively construct, reflect on, and make sense of themselves and their experiences (Boud \& Walker, 1991; Kayes, 2002). In organizational settings, constructivist approaches to learning can be seen in Chrysler's product development teams using reflection to capture lessons learned at key points in the development process (Baird, Holland, \& Deacon, 1999) or at companies such as PepsiCo and AT\&T, which train executives on reflection skills designed to enhance experiential learning (Sherman, 1994).

However, constructivist accounts of experiential learning also make several assumptions about the learning context that are not reflective of leadership development in organizations. In particular, constructivist theories position the individual as the sole translator of experience and implicitly assume that individuals can accurately reconstruct how their behaviors contributed to specific outcomes, as well as what might have happened had they behaved differently. Yet, leadership experiences are often ambiguous, involve a complex array of stakeholders, and require individuals to perform 
within highly visible and personally risky roles (Heifetz \& Linsky, 2002; McCall \& Hollenbeck, 2002; Ohlott, 2004). Due to the ambiguity and complexity of these experiences, it is often difficult for individuals to determine the causal relationship between their behavior and specific outcomes, or how behaving differently would have impacted their performance (Avolio, 2005; House, 1971; McCall \& Hollenbeck, 2002; Morris \& Moore, 2000; Pfeffer, 1977; Raelin, 1997; Roese, 1997; Yammarino \& Bass, 1991). This causal ambiguity is why Ohlott (2004) suggested that the most important leadership development questions that people must answer are "How did I behave . . . what did I do . . and what were the consequences or results of my actions?" (p. 174). In addition, leadership experiences can evoke an array of emotions (e.g., anxiety, fear, doubt) that inhibit an individual's ability to process and learn from experience (Fineman, 1997; Snell, 1988; Vince, 1998).

\section{AERs and Experience-Based Leadership Development}

Given the challenges associated with experience-based leadership development, individuals in leadership development contexts must be able to employ a systematic and deliberate processing of experiential data. In this section, we explain how AERs guide individuals through a more systematic and deliberate processing of experiential data and thereby enhance experience-based leadership development.

Relative to the unstructured and self-directed reflection processes that are often discussed in organizational research (Daude- lin, 1996; Kayes, 2002; McCall, 1998; Raelin, 1997), AERs guide individuals through a more systematic and critical evaluation of experiential data (Baird et al., 1999; Busby, 1999; Ellis \& Davidi, 2005). Through this systematic analysis, AERs shift individuals' modes of information processing from automatic and habitual to conscious and deliberate and foster greater cognitive elaboration of experiential data (Busby, 1999). To facilitate the systematic processing of experiential data, AERs consist of three components: self-explanation, data verification, and feedback (Ellis \& Davidi, 2005).

Self-explanation involves individuals systematically analyzing their own behavior and developing specific explanations for how their behavior contributed to performance. Once individuals develop a self-explanation, the data verification component asks them to imagine alternative interpretations of their experience and consider a range of alternative explanations for how their behavior contributed to performance. Thus, the self-explanation and data verification components help individuals more effectively learn from experience by clarifying the causal link between behavior and outcomes, and they promote more counterfactual thinking (Barsalou, 2008; Cheng, 1997; Chi, de Leeuw, Chiu, \& Lavancher, 1994; Roese, 1997; Spellman, 1996; Steyvers, Tenenbaum, Wagenmakers, \& Blum, 2003). Finally, the feedback component of AERs challenges individuals to develop specific recommendations for behavior change. In organizational settings, feedback is primarily focused on performance outcomes (i.e., success or failure) and originates primarily from other actors such as supervisors or peers (Kluger \& DeNisi, 1996). In AERs, however, the feedback focuses on the process and behaviors that produced the performance outcomes (Ellis \& Davidi, 2005), and focal participants are responsible for generating their own feedback about how to change their behavior and improve performance. Placing the responsibility for feedback on the focal individual should foster a more systematic analysis of the experience and, as a result, enhance learning and development (Webb, 1989). 
Complicating the leadership process further is the fact that leadership experiences can evoke an array of emotions (e.g., fear, anxiety) that limit the degree to which people are systematic and deliberate in their analysis of experiential data (Day, 2000; Fine- man, 1997; Goleman, Boyatzis, \& McKee, 2001). Indeed, people going through leadership development experiences often report feeling anxious or under pressure due to the visibility of their actions, the novelty of the experience, the many stakeholders involved, the need to work across organizational boundaries, and the uncertainty about what lessons to conclude (McCall \& Hollenbeck, 2002; McCall et al., 1988; Ohlott, 2004). However, by prompting a more systematic and elaborate analysis of experiential data, AERs should reduce these forms of uncertainty and help regulate emotions that might interfere with learning and development. In addition, the self-generated and processoriented feedback inherent in AERs should reduce the anxiety and selfpresentation pressures that come with leadership and specify clear behavior changes that can improve leadership performance going forward.

In sum, AERs enable people to more systematically analyze their developmental experiences, identify behavior changes that would improve performance, and regulate emotions that might interfere with experiential learning. Thus, individuals who go through AERs immediately following key developmental experiences should experience greater leadership development than people who do not engage in AERs.

Hypothesis 1: The relationship between AERs and leadership development is positive, such that people who go through an AER process will experience greater leadership development than people who do not go through an AER process.

\section{Boundary Conditions to the Developmental Value of AERs}

AERs are designed to promote a more structured and systematic processing of experiential data, but it is likely that individuals will vary in their ability to leverage AERs for this purpose. We expect that individuals' ability, personality, and prior experience will influence the degree to which individuals benefit from AERs.

Processing ambiguous experiential data. AERs are designed to shift individuals' modes of information processing from automatic and habitual to conscious and deliberate, but people differ in their capacity for and approach to processing ambiguous experiential data. We propose that two individual differences, cognitive ability and conscientiousness, will influence how effective people are at processing ambiguous experiential data and thus how effective people are at using AERs for experience-based leadership development.

Cognitive ability refers to individual differences in information processing capacity (Hunter, 1986). Those with higher levels of cognitive ability are able to take in and process more information and do so more efficiently than people who possess lower levels of cognitive ability (Kanfer \& Ackerman, 1989). As a result, people with greater cognitive ability should be able to process ambiguous experiential data more quickly, develop more accurate mental models of how their behavior contributed to performance, examine a broader range of counterfactuals, and more effectively determine how behavior changes will improve future performance. These information processing benefits are most evident when tasks are novel and ambiguous (Hunter \& Hunter, 1984), as is the case with leadership development experiences. For example, in leadership development contexts, people must process novel experiences where they are working across organizational 
boundaries and cultures (DeRue \& Wellman, 2009; McCall \& Hollenbeck, 2002; McCauley et al., 1994). Possessing higher cognitive ability should enable people to more quickly and efficiently develop a causal map for how their leadership behavior contributes to key performance outcomes, as well as identify what behavior changes will improve performance.

Hypothesis 2: The relationship between AERs and leadership development will be moderated by cognitive ability, such that the relationship will be stronger for individuals with greater cognitive ability and weaker for individuals with less cognitive ability.

Conscientiousness is a personality dimension that, like cognitive ability, provides insight into how people process ambiguous information (Costa \& McCrae, 1992). Conscientious individuals are self-disciplined, have high attention to detail, and are extremely deliberate in processing information. Indeed, conscientious individuals are more accurate in processing ambiguous information (McCrae \& Costa, 1987) and have greater perseverance and motivation in learning information-processing tasks (Colquitt \& Simmering, 1998). By enabling more systematic and deliberate information processing, conscientiousness should produce more efficient and accurate causal maps, as well as more specificity in the alternative scenarios that are considered during the AER. In contrast, less conscientious individuals will be less methodical and deliberate in their information processing and will be at risk of identifying the wrong causal relationships and interpreting their experiential data incorrectly.

Hypothesis 3: The relationship between AERs and leadership development will be moderated by conscientiousness, such that the relationship will be stronger for more conscientious individuals and weaker for less conscientiousindividuals.

Being open to and building on experience. Although people can imagine a range of possible causes and consequences of their behavior without any prior experience, their analysis of an experience should be more robust to the extent that people are open to considering an array of alternative explanations and have a broad range of prior work experience upon which to draw (Morris \& Moore, 2000; Roese, 1997). Thus, individuals' openness to experience and their base of prior experience should govern the impact that AERs have on their leadership development.

Openness to experience is a personality dimension that reflects an individual's imaginativeness, broad-mindedness, and willingness to engage in experiences that are novel and uncertain (Costa \& McCrae, 1992). Individuals high in openness have a strong intellectual curiosity, are more open to change, and are more willing to consider ideas and insights that might be different from their own (Barrick \& Mount, 1991). As a result, openness to experience promotes individual learning and adaptation (LePine, Colquitt, \& Erez, 2000). Drawing upon these insights, we propose that openness to experience will be particularly important for AERs and leadership development because individuals who are open to experience will consider more alternative perspectives and explanations, especially during the data verification phase. In contrast, people who are less open to experience will consider a narrower range of alternative explanations for their behavior and outcomes and thus realize less value from the AER.

Hypothesis 4: The relationship between AERs and leadership development will be moderated by openness to experience, such that the relationship will be stronger for individuals who are more open to experience and weaker 
for individuals who are less open to experience.

In terms of experience, prior research (Quinones, Ford, \& Tea- chout, 1995; Tesluk \& Jacobs, 1998) distinguishes between two experience dimensions: (a) the quantity or amount of work experience and (b) the degree of developmental challenge one has encountered in one's career. We expect both experience dimensions will influence the extent to which people are able to benefit from AERs. With respect to the quantity of experience, greater amounts of career work experience (i.e., career tenure) will correspond to more opportunities for individuals to directly perform or observe others performing the tasks that are encountered during leadership development experiences (Ford, Quinones, Sego, \& Sorra, 1992). This greater amount of experiential data should help individuals situate their current experience in a broader array of prior experiences and expand the set of alternative interpretations of experience that are considered in the AER. People who have less total experience will simply have fewer observations upon which to draw when considering alternative interpretations of their experience. Then again, research shows that greater amounts of experience can lead to the internalization of cognitive scripts and norms that are ineffective in challenging, novel experiences (Dokko, Wilk, \& Rothbard, 2009). Yet, by promoting more systematic and elaborate processing of experiential data, AERs likely will help people break free of ineffective cognitive scripts and norms, thus leading to greater learning and development.

Hypothesis 5: The relationship between AERs and leadership development will be moderated by an individual's amount of work experience, such that the relationship will be stronger for individuals with more career work experience and weaker for individuals with less career work experience.

The quantity of experience does not provide insight into the richness of experience or the challenges that people faced during their experience (Tesluk \& Jacobs, 1998). However, the second experience dimension, developmental challenge, provides information about the quality or types of experiences people have encountered during their careers. Developmental challenge reflects the degree to which one's career history includes experiences that have previously been linked to leadership development, such as novel events that require facilitating change, working across organizational boundaries, and managing demographic and cultural diversity (DeRue \& Wellman, 2009; Dragoni et al., 2009; McCauley et al., 1994). Relative to people with less developmental challenge in their background, individuals who possess a base of experience that is rich in developmental challenge should be able develop a broader array of counterfactuals, be more effective at processing novel and ambiguous information, and develop a richer understanding of how behavior changes can improve future performance (Lord \& Hall, 2005). In turn, developmental challenge should accentuate the benefits of an AER process.

Hypothesis 6: The relationship between AERs and leadership development will be moderated by the degree of developmental challenge in one's career history, such that the relationship will be stronger for individuals who have experienced greater developmental challenge and weaker for individuals who have experienced less developmental challenge.

Being emotionally capable of engaging in AERs. Developmental experiences and reflection processes such as AERs can evoke strong emotions, both positive and negative (Buunk, Collins, Taylor, VanYperen, \& Dakof, 1990; Fineman, 1997; 
Snell, 1988). Although emotions can foster more holistic and systematic information processing (Fredrickson, 1998; Schwarz \& Bless, 1991), research suggests that strong emotions, positive or negative, are associated with particular cognitive scripts (e.g., perceived threat and flight response) that interfere with learning and development (Bower, 1992). Thus, to maximize the developmental value of AERs, individuals must regulate their emotions.

Emotional stability is a personality dimension that reflects an individual's tendency to be calm and even-tempered. Neurotic individuals are more likely to experience social anxiety, stress, and impulsivity and to be unreflective (Costa \& McCrae, 1992), especially when facing novel or challenging situations. Prior research suggests that emotionally stable individuals are less susceptible to stress and severe emotional reactions when faced with novel or challenging situations (Penley \& Tomaka, 2002). We posit that emotional stability will serve as an asset to individuals going through the AER process. AERs force individuals to revisit and evaluate their own performance in a social setting, which can evoke strong emotional reactions that might create defensiveness and interfere with experiential learning. Relative to people who are less emotionally stable, individuals who are higher in emotional stability should be able to regulate their emotions more effectively and thus realize greater value from the AER.

Hypothesis 7: The relationship between AERs and leadership development will be moderated by emotional stability, such that the relationship will be stronger for more emotionally stable individuals and weaker for less emotionally stable individuals.

\section{Method}

\section{Participants and Research Design}

The study participants were 173 first-year, full-time master's of business administration (MBA) students at a large midwestern university in the United States. The average age of the sample was 27.61 years $(S D=3.65), 69 \%$ were male, and $44 \%$ were born outside of the United States. On average, participants had $51.59(S D=36.55)$ months of work experience.

Following Avolio, Reichard, Hannah, Walumbwa, and Chan's (2009) call for more quasi-experimental research in leadership studies, we tested our hypotheses using a quasi-experimental cohort design (Cook \& Campbell, 1979; Grant \& Wall, 2009). A "cohort" refers to groups of participants who follow each other through formal institutions, which in this case is an MBA program. One cohort serves as a control group, and another cohort serves as the experimental group. In this study, the control cohort $(N=80)$ consisted of first-year MBA students, and the experimental cohort $(N=93)$ consisted of first-year students who entered the same MBA program 2 years later. Thus, the two cohorts did not overlap in the 2 year MBA program.

As reported in Table 1, the control and experimental cohorts did not significantly differ on attributes previously linked with leadership (Eagly \& Johnson, 1990; Judge, Bono, Ilies, \& Gerhardt, 2002; Judge, Colbert, \& Ilies, 2004), including demographics, experience, cognitive ability, or personality (with extraversion as the only exception; see Measures section for detail on how these variables were assessed). In addition, not only were the participants similar in terms of personal 
attributes, but the MBA program was highly structured and consistent across both cohorts. The students engaged in the same curriculum with the same instructors, and all of the available extracurricular activities and developmental experiences were the same across both cohorts. The comparison data, in addition to having such a highly structured and consistent set of curricula and programming across cohorts, reduce the likelihood that our findings are subject to unknown confounds or selection- maturation biases (Cook \& Campbell, 1979).

\section{Procedure}

The study was conducted for each cohort over a 9-month period (see Figure 1). Prior to entrance into the MBA program (Month 1), participants completed online surveys that assessed individual differences related to career work experience and personality. Data on age, gender, international status, and cognitive ability were obtained via archival sources.

Table 1

Comparison of Means for Control and Experimental Cohorts

\begin{tabular}{|c|c|c|c|}
\hline & Control cohort & Experimental cohort & \\
\hline Variable & $M(S D)$ & $M(S D)$ & Mean comparison \\
\hline Age & $27.24(3.77)$ & $27.93(3.54)$ & $t=1.22$ \\
\hline Gender & $0.68(0.47)$ & $0.71(0.46)$ & $t=0.49$ \\
\hline International status & $0.44(0.50)$ & $0.44(0.50)$ & $t=0.04$ \\
\hline Cognitive ability & $635.88(72.32)$ & $635.05(70.72)$ & $t=0.08$ \\
\hline Amount of work experience & $48.61(35.84)$ & $54.13(37.15)$ & $t=0.99$ \\
\hline Developmental challenge & $2.77(0.57)$ & $2.75(0.65)$ & $t=0.22$ \\
\hline Conscientiousness & $2.73(0.24)$ & $2.67(0.28)$ & $t=1.49$ \\
\hline Emotional stability & $2.33(0.45)$ & $2.40(0.41)$ & $t=1.09$ \\
\hline Openness to experience & $2.52(0.39)$ & $2.61(0.32)$ & $t=1.75$ \\
\hline Extraversion & $2.26(0.38)$ & $2.43(0.36)$ & $t=3.07^{* *}$ \\
\hline Agreeableness & $2.53(0.32)$ & $2.56(0.31)$ & $t=0.71$ \\
\hline Leadership (Time 1) & $3.48(0.65)$ & $3.47(0.50)$ & $t=0.12$ \\
\hline Leadership (Time 2) & $3.50(0.62)$ & $3.75(0.56)$ & $t=2.55^{\circ}$ \\
\hline
\end{tabular}

Note. $\quad N=80$ for control cohort. $N=93$ for experimental cohort.

" $p<.05 . \quad * p<.01$.

With the support of MBA program administrators, we identified four developmental experiences that were consistent across cohorts, involved all students, were perceived by administrators as particularly developmental, and were not a graded part of any formal class. The four experiences were as follows: (a) a team building offsite that occurred the week prior to beginning the MBA program, (b) a 5-week leadership and teamwork simulation, (c) the search process for summer internships, and (d) a schoolwide case competition. Descriptions of these experiences are included in Appendix

A. 


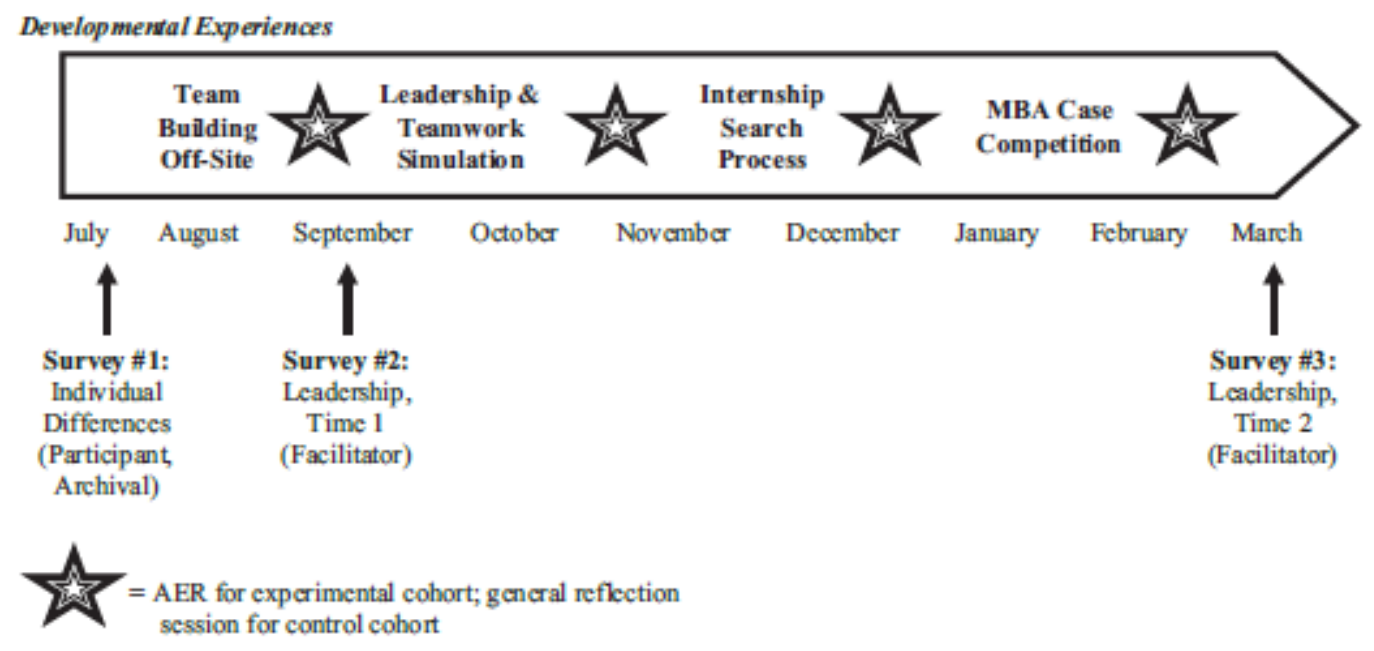

Figure 1. Study timeline. AER = after-event review.

We expected that each experience would offer an opportunity for the development of both task and relational aspects of leadership behavior. With respect to the relational aspects of leadership, the three team-based experiences required that individuals work in interdependent settings with a diverse group of people, be supportive team members, and back up other team members in their actions. Similarly, the internship search process challenged individuals' ability to build positive, trusting relationships; listen and make people feel at ease in highly stressful and uncertain environments; and manage relationships with other students they were competing with for jobs but also had to work with throughout the MBA program. With respect to the task aspects of leadership, the three team-based experiences challenged individuals to establish roles, expectations, and standards of performance, as well as coordinate task interdependencies in novel and demanding situations. Likewise, the internship search process challenged individuals to engage in many of the same leadership behaviors. For example, individuals had to coordinate tasks with key stakeholders (e.g., career services, recruiters), establish and adhere to procedures, and work within specific deadlines. It is also possible that the internship search process prompted individuals to reflect on their strengths and weaknesses related to leadership and, through enhancing their self-awareness, enabled individuals to improve their performance of task- and relationship-oriented leader behaviors.

Within 2 weeks of each experience, participants met with trained facilitators who had observed them during the experience to discuss what occurred in the experience and what could be learned from the experience. On average, these sessions lasted 30-45 min. In the experimental group but not in the control group, these meetings were structured according to an AER protocol (see below for details on the protocol). Other than the AER structure, the format of the reflection sessions (e.g., one-on-one meetings) was held constant across cohorts.

At two points in time, the assigned facilitators completed online surveys assessing the leadership behaviors of the study participant. The first point in time (Time 1) was immediately after the initial AER session (for the team building offsite). These Time 1 data provide a baseline assessment of each participant's leadership behavior. The second point in time (Time 2) was after the reflection session for the final developmental experience (the case competition), which occurred 
approximately 6.5 months after the first assessment. There was no attrition among the groups between Time 1 and Time 2.

\section{AER Process and Protocol}

Participants in both the control and experimental cohorts were assigned a trained facilitator. These facilitators were second-year MBA students who were trained by the principal investigator to observe the students during each of the four developmental experiences. The principal investigator conducted a 90-min training session with the facilitators for both the control and experimental groups. For both groups, the stated purpose of the exercise and the framing of the facilitator's roles and responsibilities were the same. The only difference was that facilitators from the experimental group were trained to use a structured AER protocol. The AER training and protocol were designed according to AER protocols created by the U.S. Army (U.S. Department of the Army, 1993). In contrast, facilitators for the control group were not trained on or asked to use a structured AER process; instead, they were told to facilitate a discussion of participants' leadership experiences and the leadership lessons learned from those experiences.

Prior to the AER session, participants prepared by answering questions about the experience as outlined in the AER protocol (see Form A in Appendix B). The protocol asked participants to reflect on the intent of the experience, their own behavior and contributions, the behavior of others, the lessons of experience, and specific actions they could take to improve future performance (Baird et al., 1999). During the AER session, participants in the experimental cohort were asked to describe their experience and explain "how did (they) contribute to the performance observed in the experience" (self explanation). Participants were also asked to consider "a different leadership approach (that) could have (been used) in this experience" and "what might have happened if (they took) that approach?" (data verification). Finally, participants were asked to develop clear conclusions about what worked, what did not work, "what (they) learned from the experience about (their) leadership capabilities," and, based on these lessons, "how (they) will lead differently in the future?" (feedback). Participants shared and discussed their responses with their trained facilitator. The facilitator supported the process by encouraging participation, using open-ended questions to guide the discussion, and entering the discussion only when necessary. At no point in the discussion did the trained facilitator provide evaluative comments or feedback to the participant. During the session, the facilitator followed an outline that guided the participant through the steps of the AER (see Appendix B). At the conclusion of each AER session, the assigned facilitator summarized the discussion using Form B in Appendix B.

For both the control and experimental groups, the trained facilitators viewed the focal participants in person during each of the developmental experiences. The trained facilitators did not actively participate in the experiences, and all study participants were aware that they were being observed and evaluated during each experience. Within 2 weeks of each developmental experience, both the control group and the experimental group had meetings with the facilitators, and the frequency and length of interaction between participants and facilitators were the same across the experimental and control groups. The only difference between the two groups was the structure of the discussions. The control group meetings comprised unstructured discussions of the four developmental experiences, whereas in the experimental 
cohort, each experience was discussed according to a structured AER process.

Given that the trained facilitators also provided the leadership behavior ratings, a potential threat to the validity of these data is that the facilitators in the experimental group were biased to see their group more favorably than those in the control group. There are several reasons why this bias is unlikely. First, because the facilitators in the control and experimental groups observed all of the same experiences and spent equal time with participants, it is unlikely that a selfserving or liking bias influenced only the facilitators in the experimental group. A comparison of means and variances for the leadership ratings supports this assertion. At Time 1, the variances in leadership ratings were different across groups ( $F=7.42, p<.05$; Levene, 1960), but using the Brown- Forsythe (Brown \& Forsythe, 1974) and Welch (1951) tests, we found no significant difference, $F(1,137)=0.01, p=.906$, in mean leadership ratings across groups. We used the BrownForsythe and Welch tests because they are robust to unequal variances (Tomarken \& Serlin, 1986). At Time 2, mean differences were present due to the proposed effect of the AER, but the variances around these means were the same, $F(1,139)=2.46, p=.119$ (Levene, 1960). These data suggest that there was an equal level and distribution of liking and disliking in both groups. Finally, our Time 1 ratings of leadership behavior occurred immediately following the first AER session. If there was a selfserving bias affecting the experimental group, we would expect to see between-group differences at Time 1, but we do not.

\section{Measures}

Participation in the AER process was dummy-coded according to whether the individual was part of the control group (0) or the experimental group (1).

Leadership development was assessed by examining the change in individuals' leadership behaviors over time (i.e., the change from Time 1 to Time 2), which is consistent with prior definitions of leadership development (Day \& Zaccaro, 2004; Klein \& Ziegert, 2004) and recent research on modeling change (e.g., DeRue \& Morgeson, 2007; Tierney \& Farmer, 2011). To assess leadership behavior at each point in time, we used a six-item measure adapted from Halpin's (1957) Leader Behavior Description Questionnaire (LBDQ). The measure included three items assessing task-related leadership behaviors such as initiating structure and three items assessing relational leadership behaviors such as consideration. We selected the six items to be included in the measure based on previously reported factor structures and item loadings for the LBDQ (Schriesheim \& Stogdill, 1975). Along a 5-point response scale (1 = strongly disagree; $5=$ strongly agree), assigned facilitators assessed the study participants using this six-item measure at Time $1(a=.83)$ and then again at Time $2(a=$ .89). To assess leadership development over time, we controlled for the Time 1 leadership behavior measure in all analyses (see Cohen, Cohen, West, and Aiken's, 2003, description of two-wave models of change).

We combined the task and relational leader behavior items into a single leader behavior measure for two reasons. First, we had no a priori theory for why AERs would differentially affect task and relational leader behaviors. Second, the correlations among task and relational leader behaviors are quite high (DeRue, Nahrgang, Wellman, \& Humphrey, 2011; Judge, Piccolo, \& Ilies, 2004). Indeed, our six items loaded onto a single factor. At Time 1, a single factor explained $62 \%$ of the variance in leadership ratings, and at Time 2 , a single factor explained $71 \%$ of the variance in leadership ratings. No 
other component had an eigenvalue over one at Time 1 or Time 2.

To ensure the validity of these leadership ratings, we also collected independent assessment data and conducted several supplemental analyses with the experimental cohort. First, at Time 1, we collected the same leadership behavior data from participants' team members. Given the intense interactions of team members during the team building offsite and 5-week teamwork simulation, we concluded that participants' team members could provide independent validation at Time 1. The correlation between facilitator and team members' ratings of leadership at Time 1 was $r=.41(p<.01)$. Second, we collected the same leadership behavior data from participants' internship supervisors approximately 2 months after our facilitators' Time 2 ratings. The correlation between the facilitator and internship

Table 2

Predictive Validity of Leadership Ratings (Time 2): Internship Offers and Salary

\begin{tabular}{|c|c|c|c|c|}
\hline \multirow[b]{2}{*}{ Variable } & \multicolumn{2}{|c|}{ Internship offers } & \multicolumn{2}{|c|}{ Internship salary } \\
\hline & Model 1 & Model 2 & Model 1 & Model 2 \\
\hline \multicolumn{5}{|l|}{ Control variables } \\
\hline Age & -.26 & & -.40 & \\
\hline Gender & -.05 & & -.05 & \\
\hline International status & -.30 & & -.34 & \\
\hline Cognitive ability & .11 & & -.04 & \\
\hline Amount of work experience & .17 & & .51 & \\
\hline Developmental challenge & .20 & & .15 & \\
\hline Conscientiousness & .13 & & .03 & \\
\hline Emotional stability & -.04 & & .09 & \\
\hline Openness to experience & .07 & & -.04 & \\
\hline Extraversion & -.20 & & .02 & \\
\hline Agreeableness & .00 & & -.04 & \\
\hline \multicolumn{5}{|l|}{ Main effect of leadership ratings } \\
\hline Leadership (Time 2) & & $.30^{*}$ & & $.33^{*}$ \\
\hline$R^{2}$ & .12 & .19 & .14 & .23 \\
\hline$\Delta R^{2}$ & & .07 & & .09 \\
\hline$\Delta F$ & 0.63 & $4.08^{*}$ & 0.69 & $4.75^{*}$ \\
\hline
\end{tabular}

Note. $\quad N=56-61$. The $N$ is less for these analyses because we focused on the experimental group only and did not have complete internship data for all participants in the experimental group. Poisson regression was used to model the effect on the number of internship offers.

$" p<.05$.

supervisor ratings of leadership at Time 2 was $r=.39(p<.05)$. We also collected data on the number of summer internship offers that individuals received as well as their summer internship salary. As reported in Table 2, after controlling for demographics, cognitive ability, work experience, and personality (see Model 1), the leadership behavior ratings at Time 2 (see Model 2) were significant predictors of both the number of internship offers received $\left(B=0.30, p<.05, A R^{2}=.07\right.$ ) and participants' internship salary $\left(B=0.33, p<.05, A R^{2}=.09\right)$. Thus, participants in the experimental cohort who were rated higher in terms of their leadership at Time 2 received more internship offers and had higher internship salaries. In sum, the facilitators' leadership behavior ratings converge with multiple, independent data sources providing both subjective leadership ratings and objective performance data.

Cognitive ability was assessed with the Graduate Management Admission Test (GMAT) (O'Reilly \& Chatman, 1994). GMAT scores were obtained from the MBA program. 
In terms of work experience, individuals' total amount of work experience was measured as the number of months of full-time employment prior to the MBA program and was obtained via archival records. Developmental challenge was measured with the Developmental Challenge Profile (DCP; McCauley, Ohlott, \& Ruderman, 1999; McCauley et al., 1994). The DCP was originally designed to assess the developmental challenge of specific job assignments. We adapted the measure by changing the scale referent to "Please indicate the degree to which each statement is descriptive of your career experience thus far . . ." All responses were recorded using a 5-point response scale $(1=$ not descriptive at all; 5 = extremely descriptive). Consistent with DeRue and Wellman (2009), a confirmatory factor analysis suggested a one- factor structure best fit these data (comparative fit index $=.97$; incremental fit index $=.97$; root-mean-square error of approximation $=.02)$. Internal consistency reliability was .94 .

Conscientiousness, emotional stability and openness to experience were measured with the Personal Characteristics Inventory (PCl; Barrick \& Mount, 1993). Each personality dimension was measured with 10 items, and the internal consistency reliabilities were .70 for conscientiousness, .78 for emotional stability, and.76 for openness to experience. We also assessed the two remaining Big 5 personality dimensions, extraversion $(a=.77)$ and agreeableness $(a=.73)$, using the same $\mathrm{PCl}$ instrument. Although we did not hypothesize effects for these two personality dimensions, we controlled for extraversion and agreeableness because both have been shown to affect individuals' leadership behaviors (DeRue et al., 2011).

We also controlled for age, gender ( 1 = male; 0 = female), and international status ( 1 = born outside of the United States, $0=$ born in the United States) to ensure that demographic differences were not an alternative explanation for our results.

\section{Results}

Table 3 provides the means, standard deviations, and intercorrelations of the study variables. The AER intervention was not correlated with Time 1 leadership behaviors but was positively correlated with Time 2 leadership behaviors, which provides some initial evidence that the AER process helped individuals engage in more effective leader behaviors over time. We used hierarchical regression (Aiken \& West, 1991) to test our hypotheses. Table 4 presents the results of these analyses. Model 1 (see Table 4) presents the main effects associated with each control variable (age, gender, international status), as well as the main effects associated with cognitive ability, amount of work experience, developmental challenge, and the Big 5 personality dimensions.

Hypothesis 1 predicted that the AER intervention would be positively related to leadership development. As presented in Model 2 (see Table 4), the AER had a positive effect on leadership development $(B=0.18, p<.01, A R 2=.03$ ). Thus, Hypothesis 1 was supported. 


\begin{tabular}{|c|c|c|c|c|c|c|c|c|c|c|c|c|c|c|c|}
\hline Variable & $M$ & $S D$ & 1 & 2 & 3 & 4 & 5 & 6 & 7 & 8 & 9 & 10 & 11 & 12 & 13 \\
\hline 2. Gender & 0.69 & 0.46 & -.02 & - & & & & & & & & & & & \\
\hline 4. Cognitive ability & 635.43 & 71.26 & .00 & .10 & $.38 * *$ & - & & & & & & & & & \\
\hline 5. Amount of work experience & 51.59 & 36.55 & $.90^{* *}$ & .02 & $.17^{*}$ & -.04 & - & & & & & & & & \\
\hline 6. Developmental challenge & 2.76 & 0.62 & $.36^{* *}$ & -.13 & $.18^{*}$ & -.03 & $.39^{* *}$ & - & & & & & & & \\
\hline 7. Conscientiousness & 2.70 & 0.27 & -.03 & -.07 & -.07 & -.03 & -.06 & .11 & - & & & & & & \\
\hline 10. Extraversion & 2.35 & 0.38 & -.14 & -.04 & .02 & -.15 & -.11 & $.19^{*}$ & $.19^{*}$ & $.26^{* *}$ & $.30^{* *}$ & - & & & \\
\hline 11. Agreeableness & 2.55 & 0.32 & .00 & $-.17^{*}$ & .00 & $-.19^{*}$ & -.01 & -.05 & $.18^{*}$ & $.24^{* *}$ & .09 & .07 & - & & \\
\hline 12. AER & 0.54 & 0.50 & .09 & .04 & .00 & .00 & .08 & -.02 & -.11 & .08 & .14 & $.23^{*}$ & .06 & - & \\
\hline 13. Leadership (Time 1) & 3.48 & 0.57 & .00 & -.04 & $-.33^{* *}$ & $-.25^{* *}$ & .04 & -.07 & .00 & .05 & -.12 & -.05 & .14 & -.01 & - \\
\hline 14. Leadership (Time 2) & 3.61 & 0.61 & -.02 & -.08 & $-.18^{*}$ & $-.18^{*}$ & -.01 & -.02 & .15 & -.02 & .00 & .12 & .07 & $.21^{*}$ & $.68^{*-}$ \\
\hline
\end{tabular}

Note. $\quad N=141-173$. AER $=$ after-event review.

${ }^{*} p<.05 . \quad * p<.01$.

Hypothesis 2 predicted that individuals with higher cognitive ability would benefit more from AERs than would individuals with less cognitive ability. As presented in Model 3 (see Table 4), individuals' cognitive ability did not moderate the effect of AERs on leadership development $(ß=0.19, n s)$. Thus, we did not find support for Hypothesis 2.

Table 4

Results of Hierarchical Regression Analysis for Leadership Development

\begin{tabular}{|c|c|c|c|}
\hline Variable & Model 1 & Model 2 & Model 3 \\
\hline \multicolumn{4}{|l|}{ Control variables } \\
\hline Age & .12 & & \\
\hline Gender & -.01 & & \\
\hline International status & .02 & & \\
\hline Cognitive ability & -.01 & & \\
\hline Amount of work experience & -.13 & & \\
\hline Developmental challenge & .01 & & \\
\hline Conscientiousness & $.14^{*}$ & & \\
\hline Emotional stability & -.05 & & \\
\hline Openness to experience & .07 & & \\
\hline Extraversion & $.17^{*}$ & & \\
\hline Agreeableness & -.01 & & \\
\hline Leadership (Time 1) & $.70^{* *}$ & & \\
\hline \multicolumn{4}{|l|}{ Main effect of AER program } \\
\hline AER & & $.18^{* *}$ & \\
\hline \multicolumn{4}{|l|}{ Hypothesized interactions } \\
\hline AER $\times$ Cognitive Ability & & & 0.19 \\
\hline AER $\times$ Amount of Work Experience & & & -0.03 \\
\hline AER $\times$ Developmental Challenge & & & $0.77^{*}$ \\
\hline AER $\times$ Conscientiousness & & & $-1.65^{*}$ \\
\hline AER $\times$ Emotional Stability & & & $-0.89^{*}$ \\
\hline AER $\times$ Openness to Experience & & & $1.20^{*}$ \\
\hline$R^{2}$ & .52 & .55 & .63 \\
\hline$\Delta R^{2}$ & & .03 & .08 \\
\hline $\overrightarrow{\Delta F}$ & $11.39^{* *}$ & $7.40^{* *}$ & $3.95^{\circ-}$ \\
\hline Model $F$ & $11.39^{* *}$ & $11.26^{* *}$ & $10.33^{* *}$ \\
\hline
\end{tabular}

Note. $N=138$. AER $=$ after-event review.

${ }^{*} p<.05 .{ }^{*} p<.01$.
Hypothesis 3 predicted that highly conscientious individuals would benefit more from AERs than would individuals who are less conscientious. As presented in Model 3 (see Table 4), conscientiousness moderated the effect of AERs on leadership development $(B=-$ $1.65, p<.05)$. We plotted the effect of the AER on leadership development for participants with high and low levels of conscientiousness (defined as 1 and -1 standard deviations from the mean, respectively; Aiken \& West, 1991). As illustrated in Figure 2, for the experimental cohort, we found that conscientiousness enhanced the degree to which AERs fostered leadership development $(B=0.16, p<.05)$. In contrast, we found that conscientiousness had a negative effect on individual learning and development for the control cohort $(\beta=-0.33, p<.05)$, which is consistent with prior research showing that conscientiousness can hinder learning in contexts where individuals are not provided the benefits of structured reflection (LePine et al., 2000). Thus, Hypothesis 3 was supported. 
In Hypothesis 4, we predicted that individuals who are open to experience would benefit more from AERs than would individuals who are less open to experience. We found that openness to experience moderated the effect of AERs on leadership development ( $\beta=1.20, p<.05$; see Model 3, Table 4). As illustrated in Figure 3, openness to experience enhanced the degree to which AERs fostered leadership development in the experimental cohort $(ß=0.17, p<.05)$, but openness to experience had no effect for the control cohort ( $\beta=-0.04, \mathrm{~ns})$. Thus, Hypothesis 4 was supported.

Hypothesis 5 stated that individuals with more career work experience would benefit more from AERs than would individuals with less career work experience. As presented in Model 3 (see Table 4), individuals' amount of work experience did not moderate the effect of $A E R s$ on leadership development $(B=-0.03, n s)$. Thus, we did not find support for Hypothesis 5.

Hypothesis 6 predicted that individuals who have experienced greater developmental challenge in their career will benefit more from AERs than will individuals who have experienced less developmental challenge. As presented in Model 3 (see Table 3), developmental challenge moderated the effect of AERs on leadership development $(ß=0.77, p<.05)$. As illustrated in Figure 4, for the experimental cohort who went through the AER process, individuals with greater developmental challenge in their careers exhibited superior leadership development relative to those individuals with less developmental challenge in their careers $(B=0.26, p<.01)$. For the control cohort, the degree of developmental challenge had no effect on leadership development ( $(=-0.07, \mathrm{~ns})$. Thus, we found support for Hypothesis 6 .

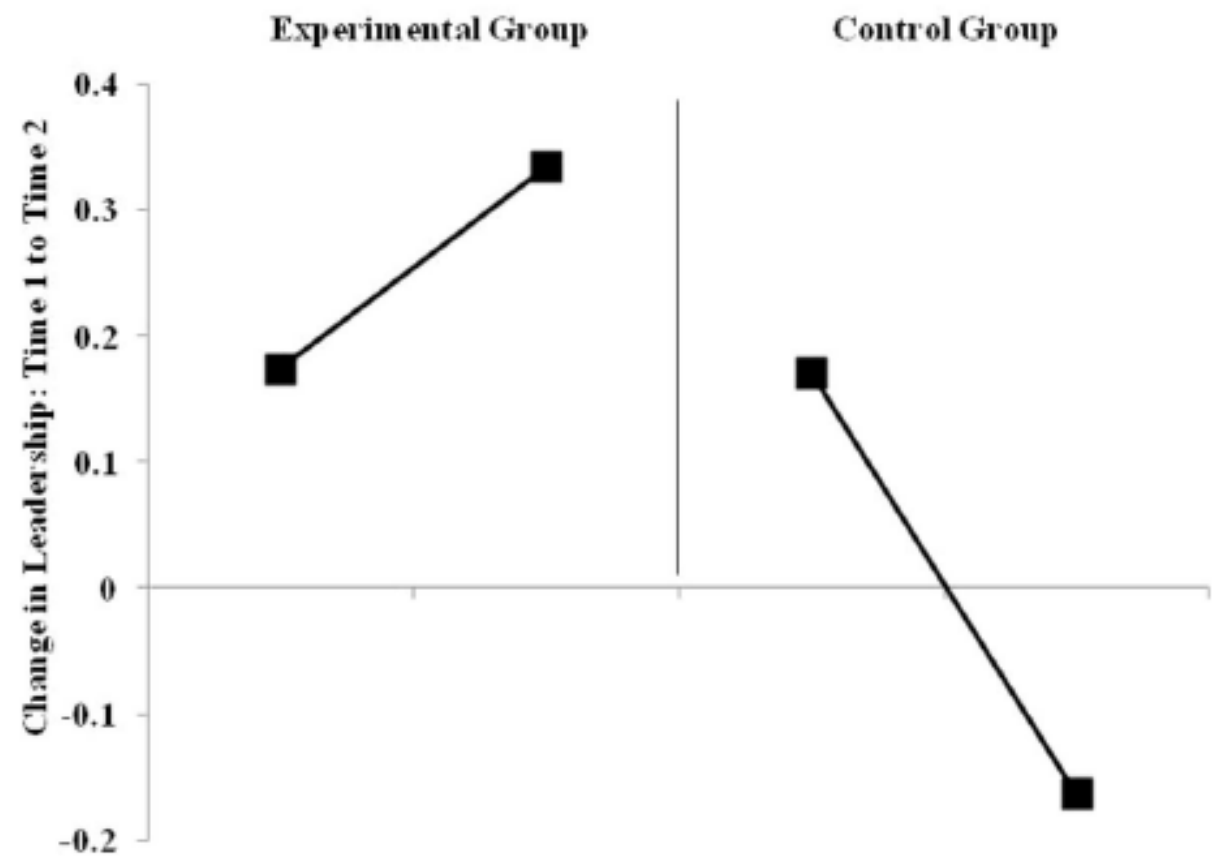

Low Conscient. High Conscient. Low Conscient. High Conscient.

Figure 2. The moderating effect of conscientiousness on the impact of AERs on leadership development. Change in leadership is equal to the slope (beta coefficient) for that condition. AERs = after-event reviews; Conscient. $=$ conscientiousness.

Finally, Hypothesis 7 predicted that emotionally stable individuals would benefit more from AERs than would individuals who are less emotionally stable. As presented in Model 3 (see Table 4), emotional stability moderated the effect of AERs 
on leadership development $(B=-0.89, p<.05)$. As illustrated in Figure 5 , emotional stability enhanced the degree to which AERs fostered leadership development in the experimental cohort ( $B=0.19, p<.05$ ), but emotional stability had no effect on leadership development in the control cohort ( $(=-0.07, \mathrm{~ns})$. Thus, Hypothesis 7 was supported.

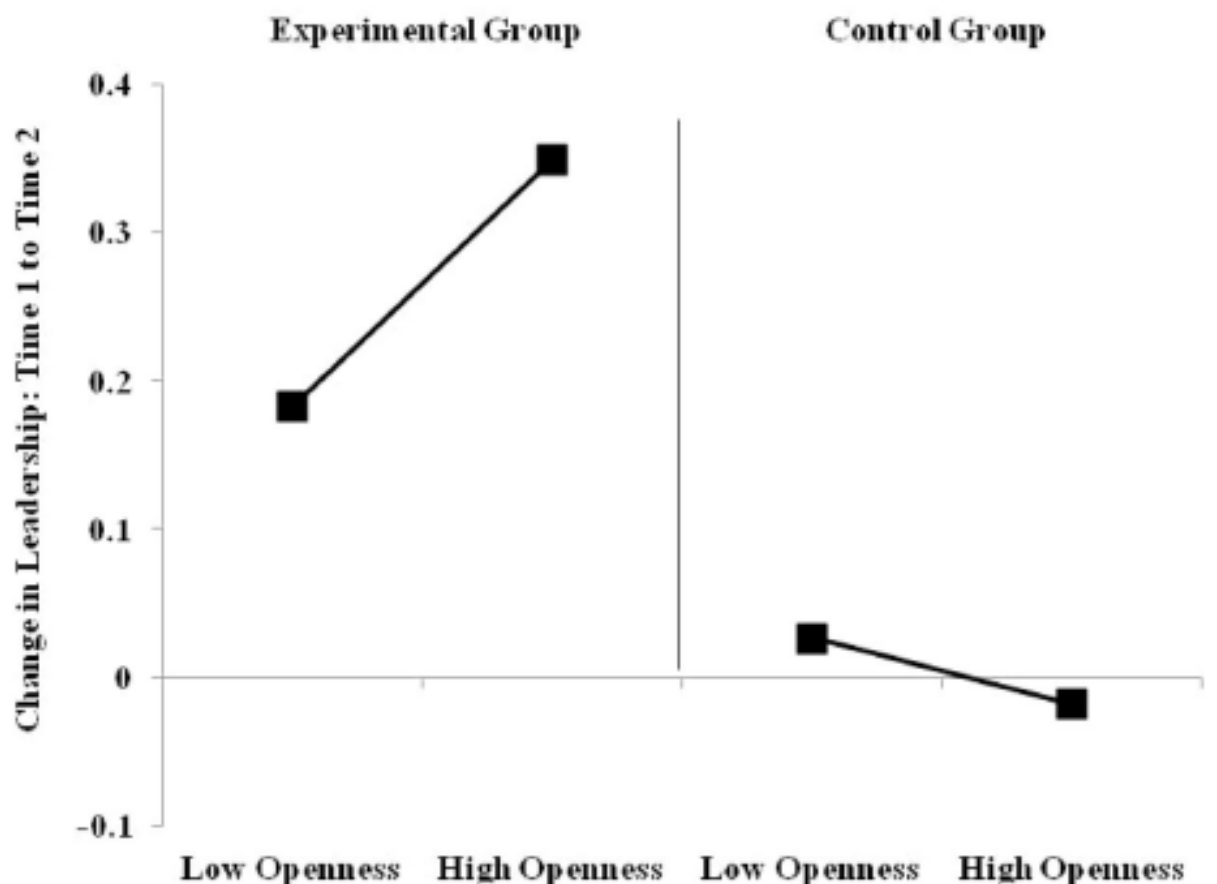

Figure 3. The moderating effect of openness to experience on the impact of AERs on leadership development. Change in leadership is equal to the slope (beta coefficient) for that condition. AERs = after-event reviews.

Overall,

the contingency effects observed for developmental challenge, conscientiousness, openness to experience, and emotional stability explained an additional $8 \%$ of the variance in leadership development above and beyond the main effect for AERs.

\section{Discussion}

\section{McCall (2010) recently stated}

It is clear that learning from experience is not automatic . . but it is not as clear what the obstacles are to learning from different kinds of experiences, or on the flip side, what might enhance it. Until more is known about these aspects of learning from experience, efforts to intervene effectively to enhance learning will continue to be hit or miss. ( p. 17)

In this article, we demonstrate that an AER is one intervention that can enhance experience-based leadership development. People who participated in AERs increased their performance of key leadership behaviors over time, whereas people who did not engage in AERs experienced little to no leadership development from the same set of developmental experiences. In addition, we specify for whom AERs are most beneficial. In particular, the developmental value of AERs was amplified for people who had a rich base of challenging career experiences, as well as those who are conscientious, open to experience, and emotionally stable. With these results in mind, we now discuss the theoretical and managerial implications of our findings. 


\section{Theoretical Implications}

Our findings offer several insights that extend existing theory and establish an agenda for future research on leadership development. To begin with, we redirect prior theory that implicitly assumes challenging, developmental experiences are both necessary and sufficient for leadership development to occur (McCall et al., 1988). Although challenging experiences offer individuals an opportunity for learning and development, our study emphasizes the importance of structured reflection for ensuring people fully capture the lessons of those experiences. We also extend constructivist theories of learning by establishing a set of boundary conditions to the learning of leadership via experience and structured reflection. In particular, we find individuals who are conscientious, open to experience, and emotionally stable and have a rich base of challenging career experiences are those who benefit most from AERs. In this sense, the developmental value of AERs is not only a function of AER type (Ellis et al., 2010) or experience (Ellis \& Davidi, 2005) but also a function of the attributes of people engaging in the AER.

In light of these findings, future research should determine how leadership development can be fostered in contexts where structured reflection is not practically possible or for people who lack the requisite career experiences and personality profiles. In addition, there are likely other individual differences or aspects of the organizational context that will influence the developmental value of AERs. For example, goal orientation (Ford, Smith, Weissbein, Gully, \& Salas, 1998; Pintrich, 2000) has been empirically linked to learning and development and might influence the extent to which individuals are willing to acknowledge their faults and opportunities for development during the AER process. Similarly, organizational contexts can often enable or constrain individual learning and development (Easterby-Smith, 1997), and research on the contextual dynamics of organizations that enable or constrain the effectiveness of AERs would go a long way toward helping organizations implement AER practices.

In terms of theoretical implications, it is also important to recognize that our findings are isolated to a particular conception of leadership development, namely, the capacity to engage in specific leadership behaviors. Although positive changes in leadership behavior are an important aspect of leadership development (Day \& Zaccaro, 2004; Klein \& Ziegert, 2004), there are other conceptions of leadership development that might also benefit from structured reflection processes such as AERs. For example, recent work on leadership development explored the processes by which individuals develop "leader" as part of their personal and social identities (Day \& Harrison, 2007; DeRue \& Ashford, 2010), and implicit in these

identity-based leadership development models is the idea that individuals reflect on their experiences in ways that promote the internalization of "leader" into their identity structure. Future research that examines the value of AERs in this identity construction process would be particularly helpful for expanding the role that AERs can play in leadership development.

Finally, our study is focused on leadership development at the individual level, but there is a need for research on grouplevel leadership development. With the emergence of shared forms of leadership (Carson, Tesluk, \& Marrone, 2007; DeRue, 2011; Morgeson, DeRue, \& Karam, 2010; Pearce, Conger, \& Locke, 2008), an important question is how structured reflection processes such as AERs can facilitate leadership development in groups. Future research could examine the 
relative validity of doing individual versus group-based AERs and explore whether the benefits of these AERs are primarily at the individual or group levels of analysis. We expect that group-based AERs would help establish more shared and accurate team mental models (Lim \& Klein, 2006), but individual-based AERs might help avoid group biases (e.g., groupthink; Janis, 1982) that could impede the learning process.

\section{Managerial Implications}

Findings from the present study have important practical implications. First and foremost, organizations should consider instituting AER processes as part of their broader leadership development strategies. However, the deployment of AERs must be done with precision. Organizations need to assess individuals' prior career histories and personality profiles to understand who within the organization is likely to benefit from AERs. Identifying in advance who is likely to benefit from AERs will enhance the return on investment for leadership development initiatives that are consistently under pressure to justify their investment.

For those individuals who do not possess the requisite experience and personality profiles, alternative approaches will be required. Life within contemporary organizations is often characterized by a focus on short-term, performance goals, and a "performance at all costs" culture can keep people from approaching their experiences with a learning orientation or reflecting on those experiences (Bruch \& Ghoshal, 2002). To shift the focus from short-term performance to learning, managers should explore ways to promote a learning-oriented and psychologically safe environment (Dweck, 1986; Edmondson, 1999) and reduce the costs of failure in developmental experiences (e.g., use simulated experiences where employees can fail with little cost). In addition, managers can implement training on AERs and design performance management systems to reward employees for engaging in AERs.

Finally, the present study has implications for leadership coaching. Most research on coaching compares the impact of coaching relative to not having a coach at all (e.g., Evers, Brouwers, \& Tomic, 2006), but the present study suggests that it is not simply the presence of a coach but rather the process that coaches use to facilitate developmental conversations that really drives leadership development. To enhance the developmental value of leadership coaching, coaches could use the AER process to structure their interactions with employees, which would shift more of the responsibility for capturing the lessons of experience onto the employee (instead of the coach). To further our understanding of how AERs can be used in leadership coaching, future research should examine how AERs can complement other coaching interventions and how the relationship between coach and employee affects the AER process.

\section{Strengths and Limitations}

The present study is not without limitations. One limitation is that the developmental experiences and AERs that were examined in this study all occurred within a structured MBA program. Thus, we cannot be sure to what extent our findings generalize to business settings. In addition, our MBA sample resulted in range restriction on select variables, notably cognitive ability, which could be an explanation for why in our study cognitive ability did not enable greater learning from AERs. Future research that examines the validity of AERs in more diverse organizational settings would clarify the external validity and application of our study's findings. 
A second limitation is that we were unable to directly assess the underlying mechanisms for why AERs, relative to unstructured reflection discussions, promote greater leadership development. Consistent with prior research (Busby, 1999; Ellis \& Davidi, 2005), we expect AERs enable more systematic and elaborate processing of experiential data, but we did not directly measure the degree to which individuals engaged in cognitive simulations, counterfactual thinking or causal analysis of ambiguous experiential data. Directly assessing these cognitive processes could have primed our control group participants that these processes would be beneficial. It is also possible that the benefits of AERs extend beyond the analysis of experience and include positive changes in relationship quality between the individual and facilitator. Following our study, future research needs to examine the underlying cognitive and relational mechanisms through which AERs promote leadership development.

A third limitation of the present study is that we collected ratings of leadership for each participant at Time 1 and Time 2 from the same source, and these are the same individuals who facilitated the AERs. This data collection approach could bias our results by introducing a same-source bias for the dependent variable. However, we do not believe our results suffer from a same- source bias for the following four reasons. First, it is unlikely that a same-source bias in our dependent variable accounts for our results, given that all other variables were either experimentally manipulated or collected via the participants themselves or archival sources. Second, we found support for a series of interaction effects using variables from multiple sources, which makes it highly unlikely that our effects are due to a same-source bias (Evans, 1985). Third, the dependent variable was operationalized as change over time and not absolute ratings of leadership. Therefore, any same-source bias in leadership ratings would be minimized by controlling for the Time 1 ratings. Fourth, within the experimental cohort, we found that the facilitator ratings at Time 1 and Time 2 converged with multiple, independent data sources, including both subjective leadership ratings and objective performance data.

A fourth limitation stems from the use of a two-wave model of change. According to Rogosa, Brandt, and Zimowski (1982), Singer and Willett (2003), and Ployhart and Vandenberg (2010), two-wave models of change assess the acquisition (increase) or loss (decrease) of a focal construct, but these two-wave models do not offer insight into the process of change or the trajectory of change. For example, similar to the trajectories observed in the 360-degree feedback literature (e.g., Reilly, Smither \& Vasilopou- los, 1996), the observed changes in leadership behavior could occur immediately following the first few AERs as individuals address their more straightforward developmental needs. Alternatively, the developmental trajectory might progress steadily over time across AERs or be delayed until a pattern of insights emerge across multiple AERs. Scholars interested in modeling the trajectory of change or the process through which AERs foster leadership development will need to employ models of change that span across three or more time periods and either randomize or counterbalance the sequence of developmental experiences to control for any differences across developmental experiences. A related concern with two-wave models of change is that the changes in leadership behavior could be the result of measurement error at Time 1 or Time 2 . We minimized this threat by using a cohort design with a control group where any measurement error that exists should be the same across the control and experimental groups (Shadish, Cook, \& Campbell, 2002). 
A final limitation is related to practical significance. The incremental variance explained by the AER was .03, so one might question the practical return on investment in AERs. We offer three reasons for why AERs are worth the investment. First, the cost of administering AERs can be quite low. In our study, participants invested only 4 hours over 9 months in the AER process. In addition, many managers already engage their employees in reflection conversations designed to enhance leadership development. The AER does not require more time, only a different structure to the reflection conversation. Second, the main effect of AERs is accentuated to the extent participants are conscientious, open to experience, and emotionally stable and have a rich base of prior developmental experiences. Considering that these personal attributes are often found in an organization's highest performers (e.g., Barrick, Mount, \& Judge, 2001), AERs become a tool that can help high achievers become even more effective. Finally, our estimate of the AER effect may actually be conservative, as developmental experiences in practice are likely more ambiguous and complex than the experiences we examined as part of a formal education program. To the extent developmental experiences are more complex or ambiguous, the return on investing in AERs should be greater.

Despite these noted limitations, the current study benefited from a variety of strengths resulting from the time-lagged, quasiexperimental design. In particular, this research design provided a valid and ethically viable approach to examining leadership over time and inferring causality regarding the effects of AERs on leadership development. In addition, we were able to minimize the potential of treatment diffusion or compensatory rivalry. Because the first cohort had graduated when the second began, we minimized the risk of study participants becoming aware of the experimental manipulation.

Finally, both the control and experimental cohorts went through the same developmental experiences. Due to the standardization of experiences and the structure of the AERs, we are able to draw inferences about the validity of AERs in experience-based leadership development. In sum, AERs are a powerful tool that organizations can use to enhance individuals' performance of key leadership behaviors.

\section{References}

Aiken, L. S., \& West, S. G. (1991). Multiple regression: Testing and interpreting interactions. Newbury Park, CA: Sage.

Anseel, F., Lievens, F., \& Schollaert, E. (2009). Reflection as a strategy to enhance task performance after feedback. Organizational Behavior and Human Decision Processes, 110, 23-35. doi:10.1016/j.obhdp.2009.05.003

Avolio, B. J. (2005). Leadership development in balance: Made/born. Mahwah, NJ: Erlbaum.

Avolio, B. J., Reichard, R. J., Hannah, S. T., Walumbwa, F. O., \& Chan, A. (2009). A meta-analytic review of leadership impact research: Experimental and quasi-experimental studies. Leadership Quarterly, 20, 764-784. doi:10.1016/j.leaqua.2009.06.006

Baird, L., Holland, P., \& Deacon, S. (1999). Learning from action: Imbedding more learning into the performance fast enough to make a difference. Organizational Dynamics, 27, 19-32. doi:10.1016/S0090- 2616(99)90027-X

Barrick, M. R., \& Mount, M. K. (1991). The Big 5 personality dimensions and job performance: A meta-analysis. Personnel Psychology, 44, 1-26. doi:10.1111/j.1744-6570.1991.tb00688.x

Barrick, M. R., \& Mount, M. K. (1993). Autonomy as a moderator of the relationships between the Big 5 personality dimensions and job performance. Journal of Applied Psychology, 78, 111-118. doi:10.1037/0021- 9010.78.1.111

Barrick, M. R., Mount, M. K., \& Judge, T. A. (2001). Personality and performance at the beginning of the new millennium: What do we know and where do we go next? International Journal of Selection and Assessment, 9, 9-30. doi:10.1111/1468-2389.00160 
Barsalou, L. W. (2008). Grounded cognition. Annual Review of Psychology, 59, 617-645. doi:10.1146/annurev.psych.59.103006.093639

Boud, D., \& Walker, D. (1991). Experience and learning: Reflection at work. Geelong, Australia: Deakin University Press.

Bower, G. H. (1992). How might emotions affect learning? In S. A. Christianson (Ed.), The handbook of emotion and memory: Research and theory (pp. 3-32). Hillsdale, NJ: Erlbaum.

Brown, M. B., \& Forsythe, A. B. (1974). Robust tests for the equality of variances. Journal of the American Statistical Association, 69, 364-367. doi:10.2307/2285659

Bruch, H., \& Ghoshal, S. (2002). Beware the busy manager. Harvard Business Review, 80, 62-69.

Busby, J. S. (1999). The effectiveness of collective retrospection as mechanism of organizational learning. Journal ofApplied Behavioral Science, 35, 109-129. doi:10.1177/0021886399351009

Buunk, B.P., Collins, R.L., Taylor, S.E.W., VanYperen, N.W.,\& Dakof, G. A. (1990). The affective consequences of social comparison: Either direction has its ups and downs. Journal of Personality and Social Psychology, 59, 1238-1249. doi:10.1037/0022-3514.59.6.1238

Carson, J. B., Tesluk, P. E., \& Marrone, J. A. (2007). Shared leadership in teams: An investigation of antecedent conditions and performance. Academy of Management Journal, 50, 1217-1234. doi:10.2307/ 20159921

Cheng, P. W. (1997). From covariation to causation: A causal power theory. Psychological Review, 104, 367-405. doi:10.1037/0033- 295X.104.2.367

Chi, M. T. H., de Leeuw, N., Chiu, M. H., \& Lavancher, C. (1994). Eliciting self-explanations improves understanding. Cognitive Science, 18, 439-477.

Cohen, J., Cohen, P., West, S. G., \& Aiken, L. S. (2003). Applied multiple regression/correlation analysis for the behavioral sciences. Mahwah, NJ: Erlbaum.

Colquitt, J. A., \& Simmering, M. J. (1998). Conscientiousness, goal orientation, and motivation to learn during the learning process: A longitudinal study. Journal of Applied Psychology, 83, 654-665. doi: 10.1037/0021-9010.83.4.654

Cook, T. H., \& Campbell, D. T. (1979). Quasi-experimentation: Design and analysis issues for field settings. Chicago, IL: Rand-McNally. Costa, P. T., \& McCrae, R. R. (1992). Revised NEO Personality Inventory.

Odessa, FL: Psychological Assessment Resources.

Daudelin, M. W. (1996). Learning from experience through reflection. Organizational Dynamics, 24, $36-48$. doi:10.1016/S0090-2616(96) 90004-2

Day, D. V. (2000). Leadership development: A review in context. Leadership Quarterly, 11, 581-613. doi:10.1016/S10489843(00)00061-8 Day, D. V., \& Harrison, M. M. (2007). A multilevel, identity-based approach to leadership development. Human Resource Management Review, 17, 360-373. doi:10.1016/j.hrmr.2007.08.007 Day, D. V., \& Zaccaro, S. J. (2004). Toward a science of leadership development. In D. V. Day \& S. J. Zaccaro (Eds.), Leader development for transforming organizations: Growing leaders for tomorrow (pp. 383-399). Mahwah, NJ: Erlbaum.

DeRue, D. S. (2011). Adaptive leadership theory: Leading and following as a complex adaptive process. Research in Organizational Behavior, 31, 125-150. doi:10.1016/j.riob.2011.09.007 DeRue, D. S., \& Ashford, S. J. (2010). Who will lead and who will follow? A social process of leadership identity construction in organizations. Academy of Management Review, 35, 627-647. doi:10.5465/ AMR.2010.53503267

DeRue, D. S., \& Morgeson, F. P. (2007). Stability and change in personteam and person-role fit over time: The effects of growth satisfaction, performance, and general self-efficacy. Journal of Applied Psychology, 92, 1242-1253. doi:10.1037/0021-9010.92.5.1242 DeRue, D. S., Nahrgang, J. D., Wellman, N., \& Humphrey, S. E. (2011). Trait and behavioral theories of leadership: An integration and metaanalytic test of their relative validity. Personnel Psychology, 64, 7-52. doi:10.1111/j.1744-6570.2010.01201.x DeRue, D. S., \& Wellman, N. (2009). Developing leaders via experience: The role of developmental challenge, learning orientation, and feedback availability. Journal of Applied Psychology, 94, 859875. doi:10.1037/a0015317

Dewey, J. (1938). Experience and education. New York, NY: Macmillan. Dokko, G., Wilk, S., \& Rothbard, N. (2009). 
Unpacking prior experience: How career history affects individual performance. Organization Science, 20, 51-68. doi:10.1287/orsc.1080.0357 Dragoni, L., Tesluk, P. E., Russell, J. E. A., \& Oh, I. S. (2009). Understanding managerial development: Integrating developmental assignments, learning orientation, and access to developmental opportunities in predicting managerial competencies. Academy of Management Journal, 52, 731-743. doi:10.5465/AMJ.2009.43669936 Dweck, C. S. (1986). Motivational processes affecting learning. American Psychologist, 41, 1040-1048. doi:10.1037/0003066X.41.10.1040 Eagly, A. H., \& Johnson, B. T. (1990). Gender and leadership style: A meta-analysis. Psychological Bulletin, 108, 233-256. doi:10.1037/0033- 2909.108.2.233

Easterby-Smith, M. (1997). Disciplines of organizational learning: Contributions and critiques. Human Relations, 50, 10851113. doi:10.1177/ 001872679705000903

Edmondson, A. (1999). A safe harbor: Social psychological conditions enabling boundary spanning in work teams. In R. Wageman (Ed.), Research on managing groups and teams: Groups in context (Vol. 2, pp. 179 -199). Greenwich, CT: JAI Press.

Ellis, S., \& Davidi, I. (2005). After-event reviews: Drawing lessons from successful and failed experience. Journal of Applied Psychology, 90, 857-871. doi:10.1037/0021-9010.90.5.857 Ellis, S., Ganzach, Y., Castle, E., \& Sekely, G. (2010). The effect offilmed versus personal after-event reviews on task performance: The mediating and moderating role of self-efficacy. Journal of Applied Psychology, 95, 122-131. doi:10.1037/a0017867

Ellis, S., Mendel, R., \& Nir, M. (2006). Learning from successful and

failed experience: The moderating role of kind of after-event review.

Journal of Applied Psychology, 91, 669-680. doi:10.1037/0021- 9010.91.3.669

Evans, M. G. (1985). A Monte Carlo study of the effects of correlated method variance in moderated multiple regression analysis. Organizational Behavior and Human Decision Processes, 36, 305-323. doi: 10.1016/0749-5978(85)90002-0

Evers, W. J. G., Brouwers, A., \& Tomic, W. (2006). A quasi-experimental study on management coaching effectiveness. Consulting Psychology Journal: Practice and Research, 58, 174-182. doi:10.1037/1065- 9293.58.3.174

Fenwick, T. J. (2003). Learning through experience: Troubling orthodoxies and intersecting questions. Malabar, FL: Krieger.

Fineman, S. (1997). Emotion and management learning. Management Learning, 28, 13-25. doi:10.1177/1350507697281002 Ford, J. K., Quinones, M. A., Sego, D. J., \& Sorra, J. S. (1992). Factors affecting the opportunity to perform trained tasks on the job. Personnel Psychology, 45, 511-527. doi:10.1111/j.17446570.1992.tb00858.x Ford, J. K., Smith, E. M., Weissbein, D. A., Gully, S. M., \& Salas, E. (1998). Relationships of goal orientation, metacognitive activity, and practice strategies with learning outcomes and transfer. Journal of AppliedPsychology, 83, 218-233. doi:10.1037/0021-9010.83.2.218 Fredrickson, B. L. (1998). What good are positive emotions? Review of GeneralPsychology, 2, 300-319. doi:10.1037/1089-2680.2.3.300 Goleman, D., Boyatzis, R., \& McKee, A. (2001). Primal leadership: The hidden driver of great performance. Harvard Business Review, 79, 42-51.

Grant, A. M., \& Wall, T. D. (2009). The neglected science and art of quasi-experimentation: Why-to, when-to, and how-to advice for organizational researchers. Organizational Research Methods, 12, 653-686. doi:10.1177/1094428108320737

Halpin, A. W. (1957). Manual for the Leader Behavior Description Questionnaire. Columbus: Ohio State University, Bureau of Business Research.

Heifetz, R. A., \& Linsky, M. (2002). Leadership on the line: Staying alive through the dangers of leading. Boston, MA: Harvard Business School Press.

Hollenbeck, J. R., Moon, H., Ellis, A. P. J., West, B. J., Ilgen, D. R., Sheppard, L., . . Wagner, J. A. (2002). Structural contingency theory and individual differences: Examination of external and internal personteam fit. Journal of Applied Psychology, 87, 599-606. doi:10.1037/ 0021-9010.87.3.599

House, R. J. (1971). A path goal theory of leader effectiveness. Administrative Science Quarterly, 16, $321-338$. doi:10.2307/2391905 Hunter, J. E. (1986). Cognitive ability, cognitive aptitudes, job knowledge, and job performance. Journal of Vocational Behavior, 29, 340-362. doi:10.1016/0001-8791(86)90013-8

Hunter, J. E., \& Hunter, R. F. (1984). Validity and utility of alternative predictors of job performance. Psychological Bulletin, 96, 72-98. doi: 10.1037/0033-2909.96.1.72 
Janis, I. L. (1982). Groupthink: Psychological studies of policy decisions and fiascoes. Boston, MA: Houghton Mifflin.

Judge, T. A., Bono, J. E., Ilies, R., \& Gerhardt, M. W. (2002). Personality and leadership: A qualitative and quantitative review. Journal ofApplied Psychology, 87, 765-780. doi:10.1037/0021-9010.87.4.765 Judge, T. A., Colbert, A.E.,\& Ilies, R. (2004). Intelligence and leadership: A quantitative review and test of theoretical propositions. Journal of Applied Psychology, 89, 542-552. doi:10.1037/0021-9010.89.3.542 Judge, T. A., Piccolo, R. F., \& llies, R. (2004). The forgotten ones? The validity of consideration and initiating structure in leadership research. Journal of Applied Psychology, 89, 36-51. doi:10.1037/0021- 9010.89.1.36

Kanfer, R., \& Ackerman, P. L. (1989). Motivation and cognitive abilities: An integrative/aptitude-treatment interaction approach to skill acquisition. Journal of Applied Psychology, 74, 657-690. doi:10.1037/0021- 9010.74.4.657

Kayes, D. C. (2002). Experiential learning and its critics: Preserving the role of experience in management learning and education. Academy of Management Learning \& Education, 1, 137-149. doi:10.5465/ AMLE.2002.8509336

Klein, K. J., \& Ziegert, J. C. (2004). Leader development and change over time: A conceptual integration and exploration of research challenges. In D. Day, S. Zaccaro, \& S. M. Halpin (Eds.), Leader development for transforming organization: (pp. 359-382). Mahwah, NJ: Erlbaum.

Kluger, A. N., \& DeNisi, A. (1996). The effects of feedback interventions on performance: A historical review, a metaanalysis, and a preliminary feedback intervention theory. Psychological Bulletin, 119, 254-284. doi:10.1037/00332909.119.2.254

Knowles, M. (1970). The modern practice of adult education: Andragogy versus pedagogy. New York, NY: Associated Press.

Kolb, D. A. (1984). Experiential learning: Experience as the source of learning and development. Englewood Cliffs, NJ: Prentice Hall.

LePine, J. A., Colquitt, J. A., \& Erez, A. (2000). Adaptability to changing task contexts: Effects of general cognitive ability conscientiousness, and openness to experience. Personnel Psychology, 53, 563-593. doi: 10.1111/j.17446570.2000.tb00214.x

Levene, H. (1960). Robust tests for equality of variances. In I. Olkin (Ed.), Contributions to probability and statistics (pp. 278 -292). Stanford, CA: Stanford University Press.

Lim, B. C., \& Klein, K. J. (2006). Team mental models and team performance: A field study of the effects of team mental model similarity and accuracy. Journal of Organizational Behavior, 27, 403-418. doi: 10.1002/job.387

Lord, R. G., \& Hall, R. J. (2005). Identity, deep structure and the development of leadership skill. Leadership Quarterly, 16, 591-615. doi: 10.1016/j.leaqua.2005.06.003

Marks, M. A., Mathieu, J. E., \& Zaccaro, S. J. (2001). A temporally based framework and taxonomy of team processes. Academy of Management Review, 26, 356-376.

McCall, M. W. (1998). High flyers: Developing the next generation of leaders. Boston, MA: Harvard Business School Press.

McCall, M. W. (2004). Leadership development through experience. Academy of Management Executive, 18, 127-130. doi:10.5465/AME .2004.14776183

McCall, M. W. (2010). Recasting leadership development. Industrial and Organizational Psychology, 3, 3-19. doi:10.1111/j.1754-9434 .2009.01189.x

McCall, M. W., \& Hollenbeck, G. P. (2002). Developing global executives: The lessons of international experience. Boston, MA: Harvard Business School Press.

McCall, M. W., Lombardo, M. M., \& Morrison, A. M. (1988). The lessons of experience: How successful executives develop on the job. Lexington, MA: Lexington Books.

McCauley, C., Ohlott, P. J., \& Ruderman, M. N. (1999). Job challenge profile: Facilitator's guide. San Francisco, CA: JosseyBass.

McCauley, C. D., Ruderman, M. N., Ohlott, P. J., \& Morrow, J. E. (1994). Assessing the developmental components of managerial jobs. Journal of Applied Psychology, 79, 544-560. doi:10.1037/0021-9010.79.4.544 
McCauley, C., \& Van Velsor, E. (2004). The Center for Creative Leadership handbook of leadership development (2nd ed.). San Francisco, CA: Jossey-Bass.

McCrae, R. R., \& Costa, P. T. (1987). Validation of the five-factor model of personality across instruments and observers. Journal of Personality andSocialPsychology, 52, 81-90. doi:10.1037/0022-3514.52.1.81

Mezirow, J. (1991). Transformative dimensions of adult education. San Francisco, CA: Jossey-Bass.

Morgeson, F. P., DeRue, D. S., \& Karam, E. P. (2010). Leadership in teams: A functional approach to understanding leadership structures and processes. Journal of Management, 36, 5-39. doi:10.1177/ 0149206309347376

Morris, M. W., \& Moore, P. C. (2000). The lessons we (don't) learn: Counterfactual thinking and organizational accountability after a close call. Administrative Science Quarterly, 45, 737-765. doi:10.2307/ 2667018

Ohlott, P. J. (2004). Job assignments. In C. McCauley \& E. V. Velsor (Eds.), The Center for Creative Leadership handbook of leadership development (2nd ed., pp. 151-182). San Francisco, CA: Jossey-Bass.

O'Leonard, K. (2010). The corporate learning factbook 2009: Benchmarks, trends and analysis of the U.S. training market. Oakland, CA: Bersin \& Associates.

O'Reilly, C. A., \& Chatman, J. A. (1994). Working smarter and harder: A longitudinal study of managerial success. Administrative Science Quarterly, 39, 603-627. doi:10.2307/2393773

Pearce, C. L., Conger, J. A., \& Locke, E. A. (2008). Shared leadership theory. Leadership Quarterly, 19, 622-628. doi:10.1016/j.leaqua .2008.07.005

Penley, J. A., \& Tomaka, J. (2002). Associations among the Big Five, emotional responses, and coping with acute stress. Personality and Individual Differences, 32, 1215-1228. doi:10.1016/S0191-8869 (01)00087-3

Pfeffer, J. (1977). The ambiguity of leadership. Academy of Management Review, 2, 104-112.

Pintrich, P. R. (2000). Multiple goals, multiple pathways: The role of goal orientation in learning and achievement. Journal of Educational Psychology, 92, 544-555. doi:10.1037/0022-0663.92.3.544

Ployhart, R. E., \& Vandenberg, R. J. (2010). Longitudinal research: The theory, design, and analysis of change. Journal of Management, 36, 94-120. doi:10.1177/0149206309352110

Quinones, M. A., Ford, J. K., \& Teachout, M. S. (1995). The relationship between work experience and job performance: A conceptual and metaanalytic review. Personnel Psychology, 48, 887-910. doi:10.1111/ j.1744-6570.1995.tb01785.x

Raelin, J. A. (1997). A model of work-based learning. Organization Science, 8, 563-578. doi:10.1287/orsc.8.6.563

Reilly, R. R., Smither, J. W.,\& Vasilopoulos, N. L. (1996). A longitudinal study of upward feedback. Personnel Psychology, 49, 3, 599 -612. doi:10.1111/j.1744-6570.1996.tb01586.x

Roese, N. J. (1997). Counterfactual thinking. Psychological Bulletin, 121, 133-148. doi:10.1037/0033-2909.121.1.133

Rogosa, D., Brandt, D., \& Zimowski, M. (1982). A growth curve approach to the measurement of change. Psychological Bulletin, 92, 726 -748. doi:10.1037/0033-2909.92.3.726

Schriesheim, C. A., \& Stogdill, R. M. (1975). Differences in factor structure across three versions of the Ohio State Leadership Scales. Personnel Psychology, 28, 189-206. doi:10.1111/j.1744-6570.1975.tb01380.x

Schwarz, N., \& Bless, H. (1991). Happy and mindless, but sad and smart? The impact of affective states on analytical reasoning. In J. P. Forgas (Ed.), Emotion and social judgments (pp. 55-71). Elmsford, NY: Pergamon Press.

Shadish, W. R., Cook, T. D., \& Campbell, D. T. (2002). Experimental and quasi-experimental designs for generalized causal inference. Boston, MA: Houghton, Mifflin.

Sherman, S. (1994, August 22). Leaders learn to heed the voice within. Fortune, 130, 92-100.

Singer, J. D., \& Willett, J. B. (2003). Applied longitudinal data analysis: Modeling change and event occurrence. London, England: Oxford University.

Snell, R. (1988). The emotional cost of managerial learning at work. Management Education and Development, 19, 322340. 
Spellman, B. A. (1996). Acting as intuitive scientists: Contingency judgments are made while controlling for alternative potential causes. Psychological Science, 7, 337-342. doi:10.1111/j.1467-9280.1996 .tb00385.x

Spreitzer, G. M., McCall, M. W., \& Mahoney, J. D. (1997). Early identification of international executive potential. Journal ofApplied Psychology, 82, 6-29. doi:10.1037/0021-9010.82.1.6

Steyvers, M., Tenenbaum, J. B., Wagenmakers, E. J., \& Blum, B. (2003). Inferring causal networks from observations and interventions. Cognitive Science, 27, 453-489. doi:10.1207/s15516709cog2703_6

Tesluk, P. E., \& Jacobs, R. R. (1998). Toward an integrated model of work experience. Personnel Psychology, 51, 321-355. doi:10.1111/j.1744- 6570.1998.tb00728.x

Tierney, P., \& Farmer, S. M. (2011). Creative self-efficacy development and creative performance over time. Journal of Applied Psychology, 96, 277-293. doi:10.1037/a0020952

Tomarken, A. J., \& Serlin, R. C. (1986). Comparison of ANOVA alternatives under variance heterogeneity and specific noncentrality structures. Psychological Bulletin, 99, 90-99. doi:10.1037/0033-2909.99.1.90

U.S. Department of the Army. (1993). A leader's guide to after-action reviews (HDQA Training Circular 25-20). Retrieved from http:// www.au.af.mil/au/awc/awcgate/ army/tc_25-20/table.htm

Vince, R. (1998). Behind and beyond Kolb's learning cycle. Journal of Management Education, 22, doi:10.1177/

304-319.

105256299802200304

Webb, N. M. (1989). Peer interaction and learning in small groups. International Journal of Educational Research, 13, 2139. doi:10.1016/0883-0355(89)90014-1

Welch, B. L. (1951). On the comparison of several mean values: An alternative approach. Biometrika, 38, 330-336.

Yammarino, F. J., \& Bass, B. M. (1991). Person and situation views of leadership: A multiple levels of analysis approach. Leadership Quarterly, 2, 121-139. doi:10.1016/1048-9843(91)90026-X 


\section{Appendix A}

\section{Developmental Experiences}

Developmental experience

Team building offsite

Leadership and teamwork simulation

Internship search process

Team-based case competition

\section{Description}

Participants were assigned to teams for the first year of the MBA program. These teams remained constant across all group assignments and extracurricular activities. The team building offsite was the first time participants worked in their teams. They engaged in a series of team-building activities, including goal-setting exercises, ropes courses, and teamwork skills exercises. The assigned facilitators were present during the entire time offsite and observed the teams as they interacted and participated in all activities.

Over the course of 5 weeks, the teams participated in the dynamic decision-making (DDD) simulation (Hollenbeck et al., 2002) 12 different times, totaling approximately 30 hours of simulation experience. The difficulty of the simulation increased over time. To perform well, participants had to engage in key team processes (e.g., strategy formulation, monitoring, coordination, conflict management; Marks et al., 2001), learn over time, and adapt to changing task environments. The assigned facilitators were present for all simulations.

The internship search process required that participants be proactive and use their communication, networking, and leadership skills to obtain a summer internship position. The process occurred over approximately 8 weeks and included many recruiting events, application processes, interviews, and offsite visits. Participants also had to negotiate their offers and make a final decision about which offer to accept. As the participants engaged in the search process, the assigned facilitators obtained progress updates every $2-3$ weeks.

The team-based case competition forced participants to work in teams and engage their strategic thinking, problem-solving, and presentation skills in a high-pressure environment. Each team was given a business case to analyze. Teams had $24 \mathrm{hr}$ to complete their case analysis and prepare a presentation for a panel of industry leaders. Teams competed for a monetary award. The assigned facilitators were present as teams prepared their analysis and presented it to the panel of judges.

\section{Appendix B}

\section{AER Protocol and Facilitator Instructions}

\section{Instructions to Facilitator}

The purpose of this critical reflection process is for the MBA student to examine and explore his/her developmental experiences in the program. The reflection process should enable the student to think about their experiences for the purposes of developing their leadership capacities and learning from these experiences.

As the facilitator, you should:

- Make a concerted effort to draw in students who seem reluctant to participate in the process

- Encourage the student to examine the experience with honesty and openness

- Enter the discussion only when necessary

- Focus the student on learning from the experience

- Use open-ended questions to guide the discussion (do not make evaluative statements)

Prior to meeting with the MBA student, please have them complete Form A. After conducting the critical reflection process, please summarize your discussion with the student using Form B. 


\section{Discussion Outline}

- Introduction and rules

- Explain the purpose of the critical reflection process and encourage participation

- Describe the experience

- Ask the student to describe the experiencewho was involved, what their role was in the experience, what happened prior to, during, and after the experience

- Awareness

- Inquire about the student's reaction to the experience, the challenges he/she faced in the experience, and the impact on his/her confidence as a leader

- Critical Analysis

- Encourage the student to critically analyze the experience, focusing on their leadership approach in the experience

- Inquire about how the student contributed to the performance outcome

- Ask the student to think of at least one alternative explanation for performance, and compare/contrast with his/her initial explanation. Encourage the student to consider "what if' scenarios.

- New Perspective

- Ask the student what lessons can be learned from the experience, and what feedback can be derived from this experience. The student should apply insights from the discussion to the experience and focus on future development opportunities

- Action Steps

- Ask the student to derive at least two actions steps that can be taken based on the lessons of this experience to improve his/her performance going forward

- Closing comments

- Gain agreement from the student on potential next steps

\section{Form A: Reflecting on the Experience}

Describe the experience

- Who was involved in this experience?

- What was your role in this experience? (Did you have to coordinate or did other people depend on you? Did you depend on other people?)

- What did you do prior to, during, and after this experience?

\section{Awareness}

- How did you react to the experience?

- How challenging was this experience? What about the experience made it challenging or not challenging?

\section{Critical Analysis}

- How did you contribute to the performance observed in this experience? (Was there an assessment of performance-what did it reveal?)

- How effective were you as a leader in this experience?

- Have you taken the same leadership approach to experiences before? How successful was it in previous situations? How effective was it in this situation? What was similar/different about these situations?

- Do other people in your team or in other teams have similar approaches to leadership as you? How does it work for them?

- What is a different leadership approach you could have taken in this experience? What might have happened if you had taken this approach?

- Did you have the competencies (e.g., technical, thinking, and interpersonal skills) needed to be effective in this experience?

\section{New Perspective}

- What did you learn from this experience about your leadership capabilities?

- Given what happened in this experience, how will you lead differently in the future?

- In what ways could you develop your leadership skills in the future? What opportunities do you have to develop further as a leader?

- In what ways do you need to change your attitudes, expectations, values, leadership approach to be a more effective leader?

\section{Action Steps}

- List at least 2 actions steps you plan on taking based on your learning from this experience.

\section{Student Name:}

Leadership Experience:

Date:

Location: 


\section{Form B: Documenting the Critical Reflection Process}

Student Name:

Facilitator Name:

Date of critical reflection:

Leadership Experience:

\section{Awareness}

- How challenging was this experience for the student? Explain.

- Did the student come to an awareness of their leadership capabilities through the experience? Why or why not?

Critical Analysis

- List the key issues that the student identified when critically analyzing the experience.

- What new perspective(s) regarding his or her leadership capability did the student take away from this experience?

\section{Action Steps}

- List the action steps the student plans on taking after this experience.

Other

- Attach Form A from the student and return. 